\title{
Contos completos de Lima Barreto: sensibilidade e rebeldia
}

\author{
Vima Lia Martin \\ Universidade de São Paulo (São Paulo, Brasil)
}

ermômetro nervoso de uma frágil República”. É assim que Lilia Moritz Schwarcz, professora titular de Antropologia da USP, qualifica Lima Barreto (1881-1922) na introdução de Contos completos de Lima Barreto (Companhia das Letras, 2010), obra organizada por ela que reúne todos os contos elaborados pelo escritor carioca, inclusive os incompletos e até então inéditos.

Fruto de um trabalho minucioso da pesquisadora no acervo da Biblioteca Nacional do Rio de Janeiro, que contou também com a colaboração de Lúcia Garcia, a edição de Contos completos divide-se em seis partes cuidadosamente constituídas, que recobrem desde os contos publicados como apêndice da primeira edição do romance Triste fim de Policarpo Quaresma (1915) até os contos publicados na segunda edição de Histórias e sonhos (1951), sem descuidar dos mais de quarenta manuscritos encontrados ao longo da pesquisa. Todo o conjunto é acompanhado por quase quinhentas notas explicativas sobre o estabelecimento dos textos e sobre termos, expressões e nomes de personagens históricas e ficcionais. Essas notas esclarecem referências mais imediatas e, certamente, atualizam a leitura dos contos. Tem-se, assim, um painel completo das narrativas curtas de Lima Barreto, que garante uma visão panorâmica fundamental para uma melhor apreciação de sua prosa.

Já no título do estudo que abre o livro, a autora apresenta uma chave valiosa para a compreensão do projeto estético-ideológico do escritor, persona complexa e multifacetada, ao estabelecer uma estreita relação entre o seu caráter irrequieto e dissonante ("termômetro nervoso") e o turbulento período histórico de que participou, marcado pelo fim da escravidão e início da República ("frágil República"). Trata-se de uma formulação que revela de forma pungente as contradições sociais filtradas pela sensibilidade aguda e dolorida de Lima Barreto. 
Vários pesquisadores da obra de Lima Barreto têm sistematicamente mobilizado a biografia do escritor para iluminar o caráter melancólico de sua obra, e o estudo de Schwarcz também recorre a esse expediente, realizando uma ampla revisão de sua fortuna crítica e trazendo para o plano da realidade concreta as possíveis causas do ressentimento que os textos deixam transparecer. $\mathrm{O}$ autor teve uma origem pobre, mas seu esforço pessoal parece ter suplantado as barreiras da escolarização que, em nosso país, até pouco tempo estava circunscrita às elites. Assim como Machado de Assis ou Florestan Fernandes, para lembrarmos duas outras figuras incontornáveis de nossa cultura, Lima valeu-se do autodidatismo para ampliar a sua compreensão do mundo.

Mulato, alcoolista, funcionário público de baixos rendimentos, o autor carioca de fato parece ter sofrido (e de maneira sistemática) inúmeros preconceitos. Como se sua própria trajetória constituísse uma denúncia exemplar de que as promessas de inclusão social e de avanço democrático embutidas no novo regime republicano eram falaciosas.

Nesse sentido, Schwarcz aponta que cor da pele provavelmente foi um entrave ao reconhecimento e à ascensão social do escritor que, em 1919, tentou, sem sucesso, entrar para a Academia Brasileira de Letras.

Nunca é demais lembrar que, num cenário social brasileiro marcado por determinismos, especialmente o racial e o geográfico, a condição dos negros e mestiços era frequentemente associada à perversão e à degeneração, e a autonomia intelectual era praticamente vetada aos "homens de cor". Daí a emergência do drama vivido por

determinados intelectuais negros (pouquíssimos por sinal) que tentavam combater o racismo científico mas esbarravam no conceito determinista de raça e em suas consequências sempre negativas. Autores como Manuel Querino, José do Patrocínio ou Lima Barreto, raros nesse contexto em que "apagar a cor" era medida cautelosa e necessária, acabaram por viver em permanente dilema, conflito e contradição entre a projetada inclusão e a realidade da exclusão social. (SCHWARCZ, 2010, p. 23-24)

Ao afirmar que Lima Barreto era portador de "uma espécie de identidade partida" (SCHWARCZ, 2010, p. 24), a autora do estudo sugere que o autor tenha vivido um "desterro intelectual" (SCHWARCZ, 2010, p. 25) e enfatiza 
os movimentos de aproximação e distanciamento travados por ele com as elites intelectuais de seu tempo, mantendo, quase sempre, uma atitude avessa à ambiência hipócrita dos círculos mais prestigiados.

Aliás, os escritos do autor, que transitam entre literatura, jornalismo, intervenção social e política, manifestam formalmente sua rebeldia diante dos padrões vigentes - as fórmulas linguísticas rebuscadas e preciosistas tão cultuadas durante a Belle Époque. O escritor tinha a consciência de que o refinamento excessivo no uso da língua estava ligado a um modelo artificial e elitista, distanciado do público leitor com quem pretendia estabelecer uma comunicabilidade direta.

Expressando frequentemente sua visada crítica sobre a realidade nacional através de uma dicção transgressora e de uma ironia de acento melancólico, Lima Barreto parece ter alimentado sua obra com o caráter problemático da sua visão sobre a sociedade e de sua pertinência a ela. Ao flagrar em seu entorno "a comédia do progresso, a força do familismo, as falácias da modernidade" (SCHWARCZ, 2010, p. 22), o escritor faz uma opção clara pelos excluídos, abordando os problemas característicos de sua condição. Seu posicionamento se torna ainda mais audacioso se considerarmos que ele se dá num momento histórico (oficial) de euforia, em que havia empenho para se apagar as marcas da colonização e da escravidão. Nas palavras de Schwarcz:

O autor constrói, assim, uma literatura que se pretende negra, suburbana e pobre. Numa época em que mais se exaltava a abolição do que se lembrava do passado escravocrata, num contexto em que o próprio Hino da República, feito apenas dois anos após a libertação dos escravos, dizia "nós nem cremos que escravos outrora tenha havido em tão nobre país", Lima Barreto fazia questão de trazer o tema para o presente (SCHWARCZ, 2010, p. 29).

Note-se que é justamente a pretensão do escritor de fazer uma literatura negra que faculta sua inserção num campo específico, o da chamada literatura afro-brasileira. A constituição desse repertório literário singular, marcado pela afirmação étnicorracial, tem como um de seus principais objetivos a reformulação da tradição literária brasileira, no sentido de torná-la mais plural e representativa. Assim, é na contramão da "brancura ideológica e estética" que pautou a consolidação de nosso cânone literário que se inscrevem os 
textos literários em que se observam posicionamentos discursivos contrários à escravidão e às suas heranças.

Como esclarece Eduardo de Assis Duarte, o reconhecimento da literatura afrobrasileira se dá no bojo da revisão que a historiografia literária brasileira tem empreendido nas últimas décadas e que implica, necessariamente, o abalo da noção de uma identidade nacional una e coesa (DUARTE, 2002, p. 47). Afinal, trata-se de contemplar também textos que expressam a sensibilidade e o imaginário dos afrodescendentes, marcados por uma experiência histórica, social e cultural bastante singular. Experiência essa que põe em xeque o mito da "democracia racial" e desmascara seus mecanismos mais ou menos sutis de discriminação.

No caso da obra de Lima Barreto, na qual, como bem lembra Schwarcz, "a ascensão social é tratada não só como aspiração, mas, sobretudo, como uma impossibilidade" (SCHWARCZ, 2010, p.25), sua inserção nessa série literária específica põe em relevo as contradições vividas pela população afrodescendente, indiscutivelmente mais sensível às injustiças sociais.

É oportuno, aqui, destacar - ao lado de Lima Barreto - outro importante contista brasileiro: João Antônio (1937-1996). Décadas depois da morte de Lima, ele também vai questionar a presença (nefasta) de uma tradição beletrista em nossa literatura e expressar uma consciência aguda e dolorida sobre a iniquidade social brasileira. João Antônio, que dedicou praticamente todos os seus livros ao autor de Policarpo Quaresma, além de escrever uma biografia sobre ele (Calvário e porres do pingente Afonso Henriques de Lima Barreto, Civilização Brasileira, 1977), inspirou-se na verve inconformada e combativa do autor carioca, a quem ele frequentemente se referia como "pioneiro". Vale recuperar uma passagem de Calvário e porres, em que João Antônio, valendo-se de um estilo espontâneo e iconoclasta, bem ao modo de Lima Barreto, discorre sobre a importância e a atualidade de seu "mestre":

Tudo de Lima é atual, de uma atualidade alarmante. Diante de seus livros, um patrimônio nacional - quatro romances do maior peso, Isaías Caminha, Policarpo Quaresma, Numa e a ninfa e Clara dos Anjos e alguns contos são fundamentais para quem se meta a conhecer literatura brasileira - nos embasbacamos. E uma pergunta nos vem, antes de outras. Mas que diabo, que bruzundanga; será possível que este País, em essência, não mudou um milímetro nos últimos cinquenta e quatro anos? (JOÃO ANTÔNIO, 1977, p. 14-15). 
Entre o Brasil de Lima Barreto e o Brasil de João Antônio, de fato muito pouco havia mudado. E mesmo hoje, depois de avanços consideráveis nos últimos anos, nosso déficit social ainda é imenso. A percepção crítica dessa realidade, que possui raízes históricas profundas, certamente se torna mais complexa e aguda com a leitura dos textos de Lima Barreto.

Graças ao excelente trabalho de Lilia Moritz Schwarcz, a leitura de todos os contos do escritor, agora finalmente compilados, permite que ampliemos a reflexão do alcance e dos limites de seu projeto literário, bem como a compreensão dos impasses históricos que nos constituem. Afinal, como bem reconhece João Antônio, Lima Barreto é um dos mais instigantes escritores brasileiros, dotado de uma lucidez e uma atualidade surpreendentes.

\section{Referências bibliográficas}

BARRETO, Lima. Contos completos. Organização e introdução de Lilia Moritz Schwarz. São Paulo: Companhia das Letras, 2010.

DUARTE, Eduardo de Assis. Notas sobre a literatura brasileira afrodescendente. In: Poéticas da diversidade. Organização de M. F. SCARPELLI e E. A. DUARTE. Belo Horizonte: UFMG/FALE, 2002.

João Antônio. Calvário e porres do pingente Afonso Henriques de Lima Barreto. Rio de Janeiro: Civilização Brasileira, 1977.

Recebido em 05 de agosto e aprovado em 15 de setembro de 2010. 